ORIGINAL ARTICLE

\title{
Cost-benefit and cost-effectiveness analysis of a disability prevention model for back pain management: a six year follow up study
}

\author{
P Loisel, J Lemaire, S Poitras, M-J Durand, F Champagne, S Stock, B Diallo, \\ C Tremblay
}

Occup Environ Med 2002;59:807-815

See end of article for authors' affiliations

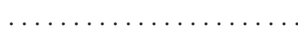

Correspondence to: Dr P Loisel, Centre de recherche clinique en réadaptation au travail PREVICAP, Hôpital Charles LeMoyne, 1111 , rue St-Charles Ouest, bureau 101, Longuevil, Québec, Canada, J4K 5G4:

patrick.loisel@usherbrooke.co

Accepted 14 May 2002
Aims: To test the long term cost-benefit and cost-effectiveness of the Sherbrooke model of management of subacute occupational back pain, combining an occupational and a clinical rehabilitation intervention.

Methods: A randomised trial design with four arms was used: standard care, occupational arm, clinical arm, and Sherbrooke model arm (combined occupational and clinical interventions). From the Quebec WCB perspective, a cost-benefit (amount of consequence of disease costs saved) and cost-effectiveness analysis (amount of dollars spent for each saved day on full benefits) were calculated for each experimental arm of the study, compared to standard care.

Results: At the mean follow up of 6.4 years, all experimental study arms showed a trend towards cost benefit and cost effectiveness. These results were owing to a small number of very costly cases. The largest number of days saved from benefits was in the Sherbrooke model arm.

Conclusions: A fully integrated disability prevention model for occupational back pain appeared to be cost beneficial for the workers' compensation board and to save more days on benefits than usual care or partial interventions. A limited number of cases were responsible for most of the long term disability costs, in accordance with occupational back pain epidemiology. However, further studies with larger samples will be necessary to confirm these results.
$\mathrm{N}$ umerous studies have described the economic impact of low back pain. In the United States, cost estimates of low back pain exceed $\$ 50$ billion when considering both health care costs and costs resulting from disability payments and work loss. ${ }^{1}$ It is also known that the majority of these costs are associated with a small number of low back pain sufferers - that is, those having prolonged disability. ${ }^{2-5} \mathrm{In}$ order to reduce the costs associated with long term disability, several authors have suggested a targeted intervention towards subjects at risk of prolonged disability. ${ }^{6-12}$ Postincidence management programmes are aimed at returning injured patients back to work as soon as possible and thus avoiding prolonged disability. ${ }^{13}$ These programmes are usually multidisciplinary and involve an active participation of the patient in the rehabilitation process. They have been shown to be beneficial by increasing the rate of return to work of low back pain patients. ${ }^{14-19}$

Although post-incidence management programmes appear to be effective in facilitating return to work, it is not known whether they reduce the costs associated with low back pain. Three publications have recently critically reviewed the cost-effectiveness of low back pain programmes, ${ }^{20-22}$ and two of these reviews addressed post-incidence management programmes. ${ }^{2021}$ Both Goossens and Evers ${ }^{20}$ and Mitchell ${ }^{21}$ concluded that the selected studies contained major flaws in economic methodology that limited the validity of the cost-effectiveness results. Although the cost-effectiveness of such programmes has not been shown, some authors assert that post-incidence management programmes have the potential of saving large amounts of money by returning patients to work rapidly and preventing chronic disability. ${ }^{9} 18$ These savings are likely, given that work absenteeism explains the bulk of the costs associated with low back pain. $^{24}$
A population based randomised clinical trial was undertaken to assess a comprehensive model of management of back pain (Sherbrooke model) aimed at returning workers with subacute back pain to their regular job. This model consisted of the combination of a clinical rehabilitation intervention and an occupational intervention that included an ergonomic component. ${ }^{25}$ After a one year follow up, this model was proven effective by returning subjects to their regular work 2.4 times quicker than subjects in the standard care arm. ${ }^{17}$ According to the hypothesis that an investment in an early intervention would allow savings in the long term by reducing costs associated with chronic disability, this paper presents the results of the cost-benefit and cost-effectiveness analysis of this model of management of back pain with a six year follow up, from the Commission de la Santé et de la Sécurité du Travail du Québec: CSST (Quebec Workers Compensation Board (WCB)) perspective.

\section{METHODS}

\section{Brief description of the trial}

The trial was implemented in the Sherbrooke area (a small town in Quebec, Canada) between 1 September 1991 and 31 December $1993^{17}$ and had the following main characteristics. The study population included workers absent more than four weeks from their regular work for occupational back pain. These workers were recruited from all workplaces with more

Abbreviations: AIC, additional intervention costs; ATC, additional total costs; CB, cost-benefit; CE, cost-effectiveness; CSST, single workers' compensation board; DFB, days on full benefit; GDP, gross domestic product; OECD, Organisation for Economic Cooperation and Development; SCDC, saved consequence of disease costs; SDFB, saved days on full benefits; WCB, Workers Compensation Board 


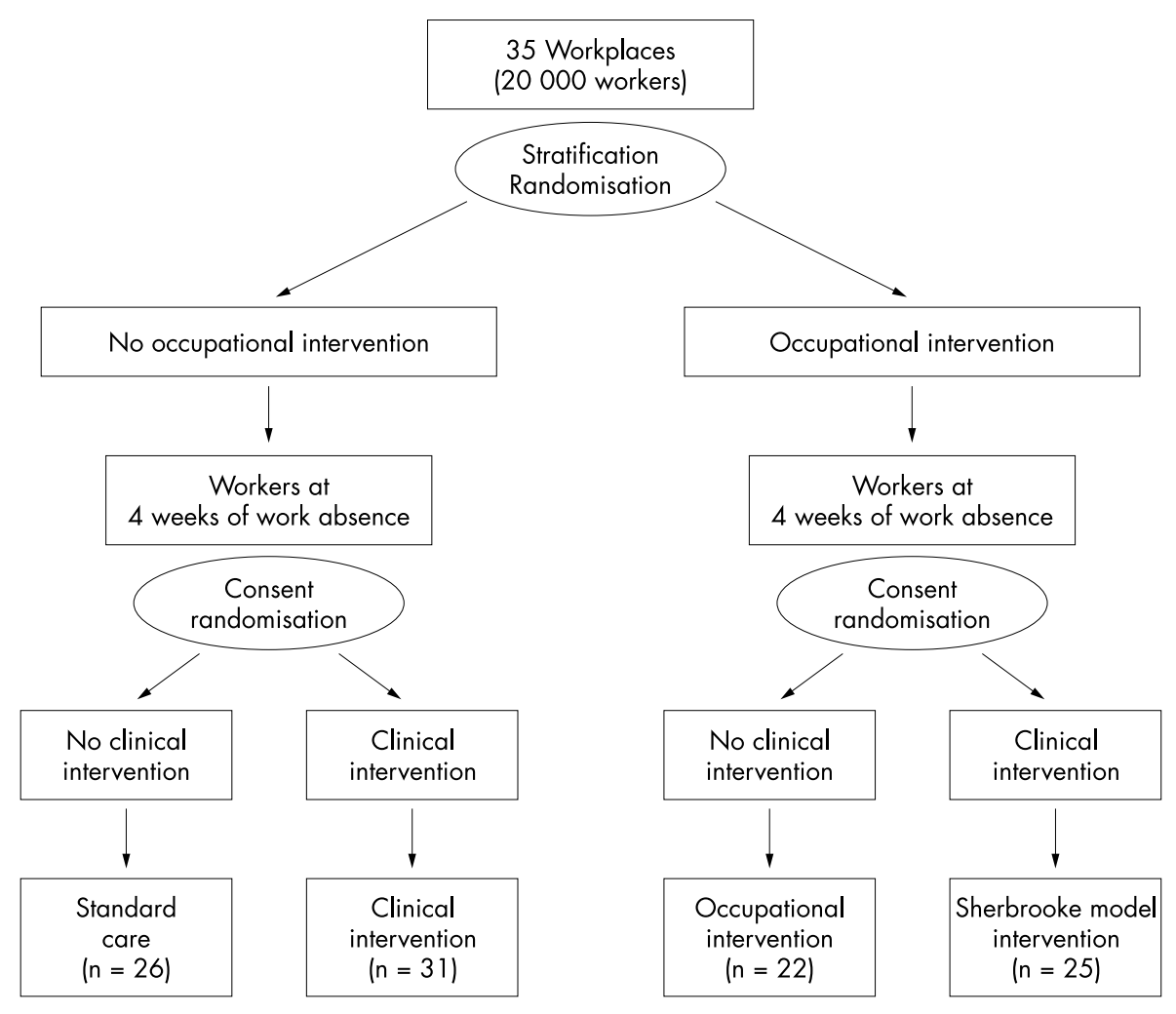

Figure 1 Cluster randomisation design resulting in the four arms of the trial. than 175 workers located in a radius of $30 \mathrm{~km}$ from the study back pain clinic. All eligible workplaces were first randomised to two arms: one in which affected workers would undergo an occupational intervention and the other in which they would not. This first randomisation was stratified according to activity sector (manufacturing, services, health care) and according to the number of employees (less or more than 500). The eligible workers in each group were randomised to receive the clinical rehabilitation intervention or not. For this randomisation, 500 random numbers were generated by a computer and were given the status yes or no for clinical and rehabilitation intervention. Each random number, along with intervention status, was placed, in order of generation, into envelopes numbered from 1 to 500. Envelopes were sealed, and the first 250 were distributed in successive order to the incoming eligible workers from the workplaces receiving the occupational intervention, and the other 250 to the incoming eligible workers from workplaces not receiving the occupational intervention. This cluster randomisation design resulted in the four arms of the trial: arm 1, standard care (control); arm 2, experimental clinical rehabilitation intervention; arm 3, experimental occupational intervention; and arm 4, combination of the two experimental interventions (Sherbrooke model; fig 1). The occupational intervention (arms 3 and 4) included visits to the study occupational medicine physician and a participatory ergonomics intervention with the study ergonomist, the injured worker, his supervisor, and management and union representatives. This participatory ergonomics intervention, intended to help workers' rehabilitation, was not an extensive ergonomics intervention as usually made in primary prevention, but limited in scope and duration. ${ }^{26} \mathrm{Job}$ modifications were recommended to the employer who was at liberty to implement them or not.

The clinical rehabilitation intervention (arms 2 and 4) consisted of a clinical examination by a back pain medical specialist, participation in a back school after eight weeks of absence from regular work and, if necessary, a multidisciplinary work rehabilitation intervention (psychologist and/or occupational therapist who oversaw a progressive return to regular tasks in a programme labelled "Therapeutic Return to Work" $)^{25} 27$ after 12 weeks of absence from work. Interventions were discontinued after return to normal job tasks, but the ergonomic evaluation was completed even if return to work happened before its completion. In all cases, return to regular work was authorised by the worker's treating physician who was advised by the back pain specialist in arm 2, by the occupational medicine physician in arm 3, and by both in arm 4 . The attending physicians of the workers included in arm 1 (standard care) received no advice about return to work.

The primary outcome of the study (on which power calculations were made) was the number of days of absence from regular work. Baseline characteristics of the recruited workers were collected through individual interview and well validated questionnaires. Initially a recruitment of 200 workers was planned but a premature closure of the recruitment was decided on before this number had been obtained and was determined by the implementation by the Quebec WCB of a new policy focused on an earlier detection of prolonged cases of sick listed workers. This policy was likely to make a co-intervention that could alter the control arm of the study. However, no comparison analysis were conducted before the study's end of follow up. The study and consent form were approved by the ethics committee of the Sherbrooke University Hospital and all participants provided written consent.

\section{Cost-benefit and cost-effectiveness analysis}

A cost-benefit and cost-effectiveness study may be conducted from various perspectives, for example, from patient, health care provider, insurer, or societal perspectives. ${ }^{28}$ In the province of Quebec, all workers declaring a work injury, and whose claims are accepted, are compensated by a single workers' compensation board (CSST). The worker is paid a non-taxable replacement income of $90 \%$ of his after tax income to a specified maximum. Usual health care costs (physicians, physical therapy, clinical tests, medication, devices, etc) and vocational rehabilitation costs are also paid by the CSST. Thus, all direct costs of compensated occupational back pain are covered by 
Table 1 Costs payers and distribution of costs for the cost-benefit and cost-effectiveness analyses

\begin{tabular}{|c|c|c|c|c|c|}
\hline & \multicolumn{3}{|l|}{ Costs payer } & \multicolumn{2}{|c|}{ Distribution of costs } \\
\hline & $\begin{array}{l}\text { Costs paid by } \\
\text { employer }\end{array}$ & $\begin{array}{l}\text { Costs paid by } \\
\text { CSST }\end{array}$ & $\begin{array}{l}\text { Costs paid by } \\
\text { grant }\end{array}$ & $\begin{array}{l}\text { Intervention } \\
\text { costs }\end{array}$ & $\begin{array}{l}\text { Consequence of } \\
\text { disease costs }\end{array}$ \\
\hline Health care costs & & $\$$ & & $\$$ & \\
\hline Income replacement costs & & $\$$ & & & $\$$ \\
\hline Occupational medicine physician & & & $\$$ & $\$$ & \\
\hline Back pain specialist & & $\$$ & & $\$$ & \\
\hline Back school & & $\$$ & & $\$$ & \\
\hline Rehabilitation & & $\$$ & $\$$ & $\$$ & \\
\hline Ergonomist & & & $\$$ & $\$$ & \\
\hline Working hours of participatory ergonomics participants & $\$ *$ & & & $\$ *$ & \\
\hline Job modifications & $\$ \dagger$ & & & $\$ \dagger$ & \\
\hline
\end{tabular}

Table 2 Characteristics of the study population at study entry

\begin{tabular}{|c|c|c|c|c|c|}
\hline & $\begin{array}{l}\text { Standard care } \\
\mathrm{n}=26\end{array}$ & $\begin{array}{l}\text { Clinical arm } \\
\mathrm{n}=31\end{array}$ & $\begin{array}{l}\text { Occupational arm } \\
n=22\end{array}$ & $\begin{array}{l}\text { Sherbrooke model } \\
\text { arm } \\
n=25\end{array}$ & $p$ value \\
\hline Mean age (y) (SD) (Q1-Q3)§ & $\begin{array}{l}41.6(10.0) \\
(33.0-48.0)\end{array}$ & $\begin{array}{l}40.2(8.5) \\
(37.0-44.0)\end{array}$ & $\begin{array}{l}44.5(5.7) \\
(42.0-48.0)\end{array}$ & $\begin{array}{l}37.4(8.1) \\
(31.0-42.0)\end{array}$ & $0.02 *$ \\
\hline Males (n) $(\%)$ & $21(81)$ & $18(58)$ & $13(59)$ & $10(40)$ & $0.03 \dagger$ \\
\hline Mean body mass index (SD) (Q1-Q3)§ & $\begin{array}{l}25.8(3.3) \\
(23.2-27.5)\end{array}$ & $\begin{array}{l}24.6(4.0) \\
(21.2-28.4)\end{array}$ & $\begin{array}{l}25.5(4.6) \\
(22.1-29.1)\end{array}$ & $\begin{array}{l}24.7(4.2) \\
(21.3-27.1)\end{array}$ & $0.66 \ddagger$ \\
\hline $\begin{array}{l}\text { Mean days of absence from work before entry in } \\
\text { study (SD) (Q1-Q3)ई }\end{array}$ & $\begin{array}{l}38.3(13.4) \\
(29.0-44.0)\end{array}$ & $\begin{array}{l}39.6(12.7) \\
(30.0-45.0)\end{array}$ & $\begin{array}{l}44.8(18.6) \\
(33.0-55.0)\end{array}$ & $\begin{array}{l}43.8(13.3) \\
(30.0-55.0)\end{array}$ & $0.35^{*}$ \\
\hline Mean Oswestry score (SD) (Q1-Q3)§ & $\begin{array}{l}29.8(14.7) \\
(18.0-42.0)\end{array}$ & $\begin{array}{l}33.7(14.6) \\
(26.0-42.0)\end{array}$ & $\begin{array}{l}30.0(18.0) \\
(16.0-38.0)\end{array}$ & $\begin{array}{l}31.1(15.6) \\
(20.0-42.0)\end{array}$ & $0.77 \ddagger$ \\
\hline $\begin{array}{l}\text { Mean Sickness Impact Profile score (SD) } \\
(Q 1-Q 3) \S\end{array}$ & $\begin{array}{l}15.8(8.9) \\
(10.0-21.0)\end{array}$ & $\begin{array}{l}15.2(6.6) \\
(10.0-21.0)\end{array}$ & $\begin{array}{l}13.2(8.9) \\
(6.0-18.0)\end{array}$ & $\begin{array}{l}13.9(8.7) \\
(8.0-16.0)\end{array}$ & $0.44^{*}$ \\
\hline $\begin{array}{l}\text { Mean pain level (McGill-Melzack questionnaire) } \\
\text { (SD) (Q1-Q3)§ }\end{array}$ & $\begin{array}{l}22.9(14.2) \\
(13.0-28.0)\end{array}$ & $\begin{array}{l}28.5(18.4) \\
(14.0-43.0)\end{array}$ & $\begin{array}{l}22.9(19.5) \\
(8.0-30.0)\end{array}$ & $\begin{array}{l}27.0(27.7) \\
(12.0-35.0)\end{array}$ & $0.42 *$ \\
\hline Mean work APGAR satisfaction (SD) (Q1-Q3)§ & $\begin{array}{l}11.3(2.4) \\
(10.0-13.0)\end{array}$ & $\begin{array}{l}11.1(2.2) \\
(10.0-12.0)\end{array}$ & $\begin{array}{l}10.9(3.1) \\
(8.0-14.0)\end{array}$ & $\begin{array}{l}11.1(2.7) \\
(9.0-14.0)\end{array}$ & $0.94^{*}$ \\
\hline Mean income (1991 Canadian \$) (Q1-Q3)§ & $\begin{array}{l}31313 \\
(25383-38196)\end{array}$ & $\begin{array}{l}29940 \\
(24395-32217)\end{array}$ & $\begin{array}{l}27234 \\
(25549-29402)\end{array}$ & $\begin{array}{l}26174 \\
(24786-26889)\end{array}$ & - \\
\hline
\end{tabular}

*Non-parametric comparison (Kruskal-Wallis test) when non-normal and/or unequal variances.

†Comparison of proportions $\left(\chi^{2}\right.$ test).

$\ddagger$ Comparison of means (ANOVA).

$\S Q 1$ : first quartile; Q3: third quartile.

the CSST and few indirect costs related to treatment are paid by the worker or other parties in Quebec. For this reason, the present study was designed from the CSST (insurance provider) perspective and includes only direct costs paid by the CSST. The cost-benefit analysis was performed by using outcomes expressed in monetary terms. The cost-effectiveness analysis was performed by using the outcome of number of fully compensated days because of back pain. ${ }^{28}$

\section{Description of costs}

For each accepted WCB claim for a work injury, the CSST opens a file and registers all eligible health care and income replacement costs associated with that work injury. The following costs were calculated for each worker during the follow up period: income replacement costs, usual health care costs, and experimental intervention costs. In addition to the usual health care costs paid by the CSST, each experimental arm generated specific experimental interventions costs. Some of these interventions, considered unusual in the standard treatment of subacute back pain by the CSST, were not paid by the CSST but by the research grant allocated to the project. These costs are described in 1991 Canadian dollars as follows. Occupational medicine physicians were paid at the regular physician rate in the province of Quebec ( $\$ 50$ for the first visit and \$20 for follow up visits). The ergonomist was paid an hourly rate of $\$ 50$ (usual CSST salary for an ergonomist). Work hours spent by workplace employees in the participatory ergonomics intervention, paid by employers, was noted and hourly costs for each participant was estimated in the following way: $1.2 \times$ average employee wages for the union representative, $2.0 \times$ average employee wages for the worker's supervisor, and $2.0 \times$ average employee wages for the employer's representative. The following costs were accepted and paid by the CSST but, in the context of the study, were costs related to the experimental interventions: back pain specialist visits ( $\$ 50$ for the first visit and $\$ 20$ for follow up visits) and back school (\$600). These costs were calculated as experimental intervention costs but deducted from the usual health care costs in the CSST files to avoid double accounting. The CSST did not pay for the experimental "Therapeutic Return to 


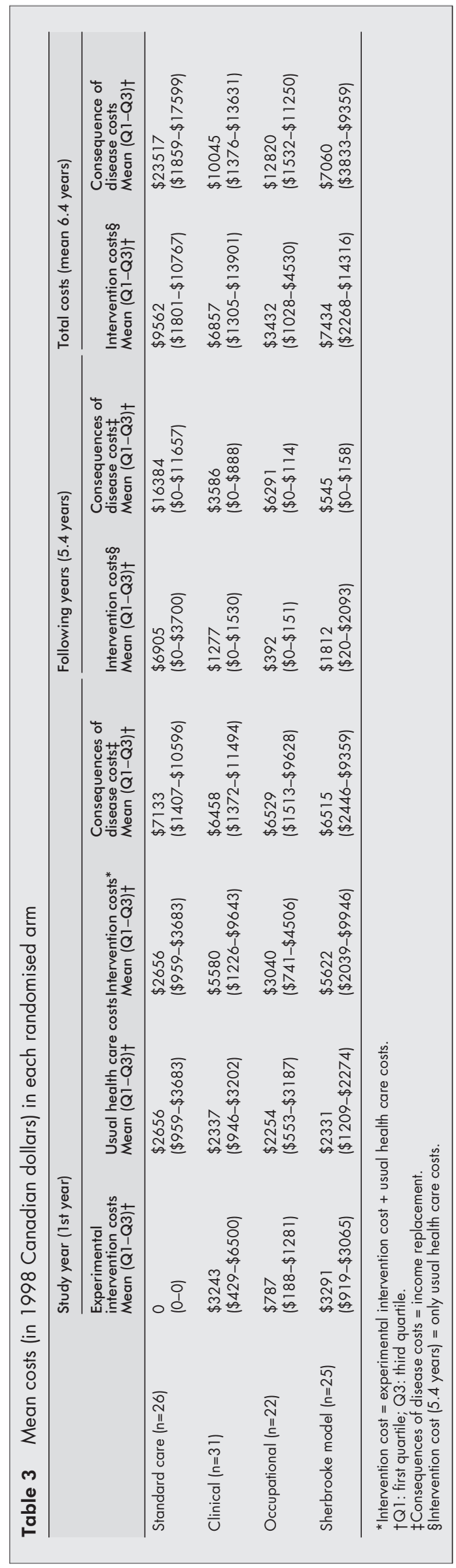

Work" programme because they did not consider the cases as chronic. Instead, they paid the cost corresponding to a regular occupational therapy treatment ( $\$ 29$ per day). The cost for the experimental rehabilitation intervention was $\$ 168$ - that is, the amount usually allocated by the CSST for multidisciplinary interventions for recognised chronic back pain patients. This cost was added to experimental intervention costs and the \$29 paid by the CSST was deducted from the CSST health care costs. Costs related to job modifications recommended by the ergonomist in the occupational interventions that were implemented and paid by the employers (not the CSST) were not included in this economic evaluation. Table 1 summarises the distribution of costs.

\section{Cost-benefit and cost-effectiveness analysis method}

The statistical department of the CSST retrieved all registered costs for all workers included in the study from the date of the work accident to 31 December 1998. As back pain recurrences or new episodes of back pain could have been registered by the CSST under a new file number, subsequently accepted back pain claims with time loss or health care costs following the initial back pain episode were retrieved using the worker's social insurance number. All health care and income replacement costs associated with subsequent episodes of compensated back pain for the initial study subjects were identified from these data. The same inclusion and exclusion criteria used for back pain accidents in the original study were used for recurrences in this study. ${ }^{17}$ Absences for causes other than back pain were excluded. These data were transferred to SAS version 6.12 for analysis (SAS Institute, Cary, NC).

For each worker, CSST costs (income replacement and health care costs) were compiled at the end of the intervention period (first year) and at the end of the follow up period (31 December 1998). Income replacement costs and costs of time spent in the participatory ergonomics intervention depended on the worker's individual income, which was different for each worker in order to make comparison of costs between arms; individual income was standardised to the average income of workers in the control arm (an income dependent cost was multiplied by the ratio of the mean income of the workers in the standard care arm over the individual worker's income).

All income related costs were adjusted to 1998 Canadian dollars according to the Quebec all items inflation rates, and all usual health care and experimental intervention costs were adjusted to 1998 Canadian dollars according to the health care inflation rates. ${ }^{29}$ Both cost-benefit and cost-effectiveness analyses were performed for the first year (year of the interventions), and for the total follow up period (mean of 6.4 years).

\section{Cost-benefit analysis}

When an individual suffers from a disease, there are costs associated with the consequences of the disease. In this study, the costs to the CSST associated with the consequences of work related low back pain were income replacement costs. The cost-benefit analysis assessed the capacity of the experimental interventions to reduce the consequence of disease costs when compared to costs related to standard care. For each experimental arm, the cost-benefit (CB) of the intervention was calculated using the following equation: $\mathrm{CB}=$ SCDC - AIC, where SCDC is the saved consequence of disease costs against standard care and AIC is the additional intervention costs compared to standard care.

\section{Cost-effectiveness analysis}

Days on full benefits (DFB) because of back pain was the outcome used for the cost-effectiveness analysis. By Quebec law, when a worker is considered as permanently disabled from an occupational injury and for this reason unable to fulfil 


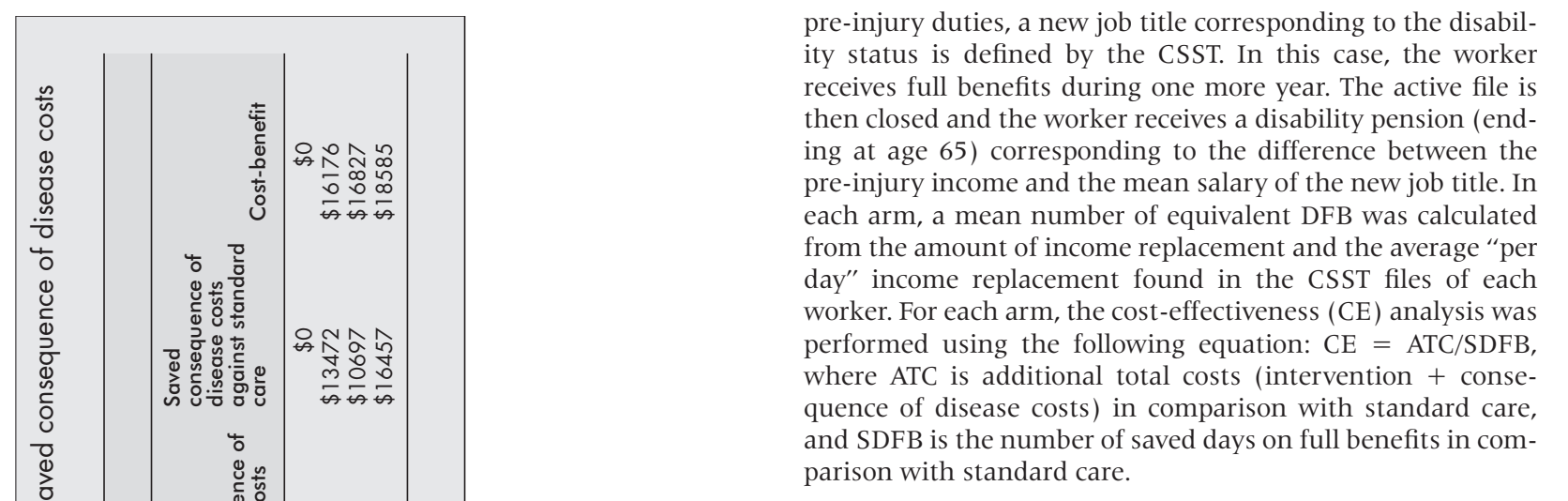

Sensitivity analysis

A sensitivity analysis was performed to assess the impact of economic variations between countries on the cost-benefit and cost-effectiveness results. ${ }^{28}$ Using Organisation for Economic Cooperation and Development (OECD) data of major industrialised countries, experimental intervention and health care costs were varied according to the total expenditure on health per capita, while income replacement costs were varied according to the mean income per capita estimated with the gross domestic product (GDP) per capita based on purchasing power parities. Health care costs varied from about $60 \%$ to $190 \%$ of the Canadian health care costs, ${ }^{30}$ while mean income per capita varied from about $85 \%$ to $125 \%$ of the Canadian GDP per capita. ${ }^{31}$ Sensitivity analyses were performed for the total follow up period using the lower and upper limits of these variables.

\section{Statistical analysis}

Comparisons between arms on characteristics of the study population (table 2 ) were done by $t$ tests/analysis of variance or, when the parametric analysis was not appropriate, by nonparametric analysis of Wilcoxon/Kruskal-Wallis for continuous variables and by $\chi^{2}$ tests or Fisher exact tests for dichotomous variables. Comparisons between costs were made by a Kruskal-Wallis non-parametric analysis. A comparison of proportion of high cost patients between arms was made with a Fisher exact test. In order to take into account confounders, a logistic regression has been attempted on dichotomous variables. Exact confidence limits for the binomial proportion of high cost patients of each arm were calculated by SAS-PROC FREQ/BINOMIAL/EXACT. All data management and statistical analysis were performed with SAS release 6.12, and later on SAS release 8.00 (SAS Institute Inc., Cary, NC, USA).

\section{RESULTS}

Thirty one workplaces, among the 35 which were eligible, participated in the study and only one withdrew after one year of study participation. These workplaces were distributed in the following sectors: 14 in manufacturing, seven in health care, and 10 in services sectors. Table 2 describes the main characteristics of the study population. ${ }^{17}$ From the 31 participating workplaces, 130 workers accumulated four weeks of absence from regular work, accepted to participate in the study, and were randomised. Fourteen of the 130 randomised workers failed to meet the inclusion criteria (non-cases) and 12 workers did not respond to any follow up visit (non-participants). Both the non-cases and the non-participants were distributed in the four randomisation groups. Hence, analyses were performed on 104 participants. The participants did not differ from the non-participants in gender, duration of absence from regular work, or clinical data, but the participants were older. The 104 participants were distributed in the following way: standard care arm, $\mathrm{n}=26$; clinical rehabilitation arm, $\mathrm{n}=31$; 
Table 5 Number and percentage of very costly cases in each arm and comparison between arms

\begin{tabular}{llcc}
\hline & \multicolumn{3}{l}{ Number of patients exceeding total cost of $\$ 65000$} \\
\cline { 2 - 4 } & Number & $\%$ & $95 \% \mathrm{Cl}^{*}$ \\
\hline Standard care $(\mathrm{n}=26)$ & 4 & 15.4 & 4.4 to 34.9 \\
Clinical $(\mathrm{n}=31)$ & 0 & 0.0 & 0.0 to 11.2 \\
Occupational $(\mathrm{n}=22)$ & 1 & 4.5 & 0.1 to 22.8 \\
Sherbrooke model $(\mathrm{n}=25)$ & 0 & 0.0 & 0.0 to 13.7 \\
Fisher exact test (two sided) & & $\mathrm{p}=0.0201$ & \\
\hline
\end{tabular}

*Exact confidence limits for the binomial proportion (PROC FREQ/BINOMIAL, SAS release 8.00).

occupational arm, $\mathrm{n}=22$; and Sherbrooke model arm, $\mathrm{n}=25$. At baseline, there were no significant differences in body mass index, duration of absence from work, specific and generic functional disability (Oswestry and Sickness Impact Profile questionnaires), pain level (McGill-Melzack), and work satisfaction (Work APGAR) between subjects in each arm $(p>0.05)$. However, there was a statistically significant difference in age and sex between arms $(\mathrm{p}<0.05)$ (table 2$)$.

The mean follow up period was 6.4 years, with a range of 5.1-7.5 years depending on worker enrolment in the study. There were no significant differences in follow up times between arms ( $\mathrm{p}=0.93$; Kruskal-Wallis). The following costs are given in 1998 Canadian dollars. Table 3 shows mean costs for each arm at the end of the intervention period and at the end of the follow up. The highest experimental intervention costs were found in the Sherbrooke model arm (mean \$3291 per worker) and in the clinical arm (mean $\$ 3243$ per worker) but were less important in the occupational arm (mean $\$ 787$ per worker). The standard care arm had no experimental intervention costs.

\section{Cost-benefit analysis}

As usual health care costs were similar in the three experimental arms (table 3), total intervention costs followed the previous pattern of experimental interventions costs. Consequence of disease costs at one year follow up were higher in the standard care arm (\$7133) than in the experimental arms (respectively $\$ 6458, \$ 6529, \$ 6515$ ) and much higher in the 5.4 following years (\$16384 compared to \$3586, \$6291, and $\$ 545)$. It resulted that the highest total consequence of disease costs at the mean 6.4 years follow up were found in the standard care arm (\$23 517) and the lowest in the Sherbrooke model arm (\$7060). The clinical $(-\$ 2250)$ and Sherbrooke model arms (-\$2348) were not cost-beneficial during the first year following the intervention compared to the standard care arm (negative cost), and the occupational arm was moderately cost-beneficial (\$220) (table 4). Over the course of the total follow up period (mean 6.4 years) all experimental interventions were cost-beneficial with savings in the Sherbrooke model arm (\$18 585) moderately higher than those in the clinical (\$16 176) and the occupational (\$16 827) arms. However, the difference between arms was not statistically significant ( $\mathrm{p}=0.48$; Kruskal-Wallis).

Figure 2 plots for each arm the percentage of patients cumulating a cost amount with the total costs at the mean 6.4 years follow up. Five costly cases exceeded a total cost of $\$ 65000$ (average total cost for these cases $=\$ 150$ 814). Table 5 shows the distribution of these cases in each arm. Four costly cases appeared in the standard care arm and one such case in the occupational arm. In the clinical and Sherbrooke model arms, there was an absence of very costly cases. Differences in proportions of these costly cases between arms were significant $(p=0.020$; Fisher exact). These five costly cases had no statistically significant difference in age $(p=0.39$; $t$ test) or sex ( $\mathrm{p}=0.65$; Fisher exact test) with the remaining study population $(\mathrm{n}=99)$. They were employed in five different workplaces-one in health care, two in manufacturing,

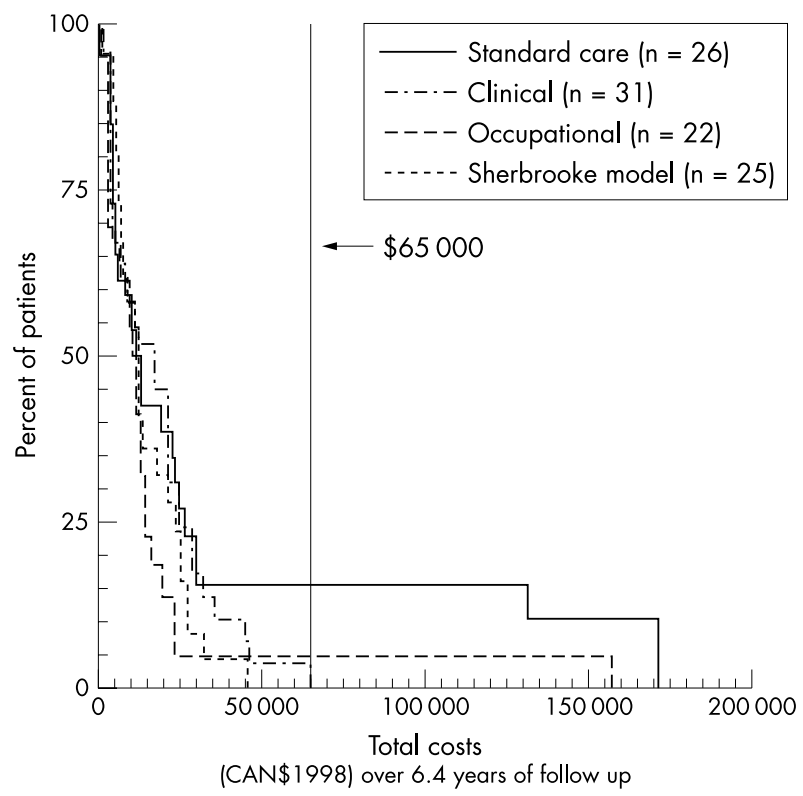

Figure 2 Percentage of patients' cumulating costs with the total costs at the mean 6.4 years follow up for each arm.

and two in services industrial sectors-and all had different job titles. A logistic regression analysis was tried in order to take into account age and sex confounders but was not deemed possible ("Quasicomplete separation of data points detected").

\section{Cost-effectiveness analysis}

During the total follow up period, the mean number of days on full benefits (DFB) because of back pain was the highest in the standard care arm with a mean of 418.3 days, while it was the lowest in the Sherbrooke model arm with a mean of 125.6 days. The clinical and occupational arms had respectively a mean of 178.7 and 228.0 DFB because of back pain (table 6). All experimental interventions saved DFB when compared to the standard care arm. In the first year, the mean total costs per saved DFB were \$187.4 in the clinical arm, $-\$ 20.4$ in the occupational arm, and \$213.5 in the Sherbrooke model arm. The total number of saved DFB during the total follow up period was 239.6 days for the clinical arm, 190.3 days for the occupational arm, and 292.7 days for the Sherbrooke model arm (table 6). During the total follow up period, the mean total costs per saved DFB were $-\$ 67.5$ in the clinical arm, -\$88.4 in the occupational arm, and $-\$ 63.5$ in the Sherbrooke model arm (table 6). These negative costs are caused by the fact that at the mean 6.4 years follow up the total costs were less important in the experimental arms than in the standard care arm (less money was finally spent to save days on full benefits). 


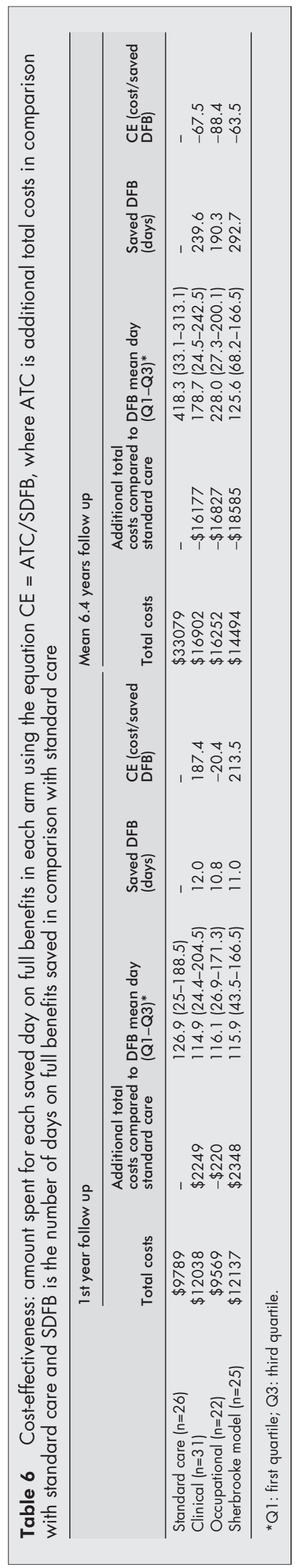

\section{Sensitivity analysis}

Sensitivity analyses were performed for the total follow up period. In each experimental arm, the cost-benefit (amount of consequence of disease costs saved) varied in the following way: clinical arm: from $\$ 13074$ to $\$ 21$ 978; occupational arm: from \$12 770 to $\$ 25018$; and Sherbrooke model arm: from $\$ 15265$ to $\$ 24614$. The cost-effectiveness (total amount of dollars spent for each saved DFB) varied in the following way: clinical arm: from $-\$ 6.77$ to $-\$ 21.44$; occupational arm: from $-\$ 19.33$ to $-\$ 61.21$; and Sherbrooke model arm: from $-\$ 4.36$ to $-\$ 13.81$.

\section{DISCUSSION}

The hypothesis of this study was that an early investment in appropriate interventions of disability prevention would allow savings in the long term. The results indicate an important trend in this way. The Sherbrooke model arm was the most cost-beneficial at the mean 6.4 years follow up with a mean saving of \$18 585 per worker. However, in spite of the large amounts saved, there was no statistically significant difference between the four arms. This was possibly caused by the skewed distribution of the costs (fig 2), because of a few very costly cases and to the limited number of the study population. This should not be considered as a bias or artefact but in relation to the behaviour of occupational back pain as it has been reported in many epidemiological studies ${ }^{132}$ : a few cases are responsible for the majority of the costs. To our knowledge, this is the first observation of this cost pattern in an intervention study. Even if, because of the limited study sample, only five very costly cases appeared, the difference in their distribution between arms was statistically significant $(p=0.020)$. However, further studies with larger samples will be necessary to confirm these results.

As this study was population based, selection biases in the study population were unlikely and the long term cost-benefit for the CSST is readily apparent. Obviously, most of the savings were income replacement savings and correspond to cases of prolonged absence that were avoided in the intervention groups, unlike the standard care arm that behaved according to the natural history of occupational back pain. With the exception of experimental intervention costs, all the costs recorded in this study were CSST costs. In this way, these results suggest that spreading such an innovative model of management of back pain or its occupational or clinical/ rehabilitation parts might be of economic benefit for workers' compensation boards or disability insurers. Moreover, as the experimental interventions allowed for a reduction of duration of time on full benefits (that grossly correspond to duration of absence from work) over the long term, the experimental interventions were not only cost-beneficial but also very cost-effective with less total money spent to save days on benefits. Also, as these five cases varied in age, gender, workplace, workplace sector, and job title, a bias caused by these variables is unlikely.

All the recorded costs were true expenses disbursed by the CSST or the research team, with the exception of estimated costs of the employer and union representatives' salaries for time spent in participatory ergonomics meetings. As these salary costs represented less than $2 \%$ of the recorded costs in the occupational and the Sherbrooke model arms, sensitivity analyses were not deemed necessary for these costs. The results of the sensitivity analyses on economic variations in health care and income costs were only an attempt to test the stability of the cost benefit results despite variation in workers' income or health care costs as may be observed in different countries. However, disability or return to work are influenced by many other psychological, cultural, and employment factors that may also vary from one country to another, and these results might not directly apply to other countries. 


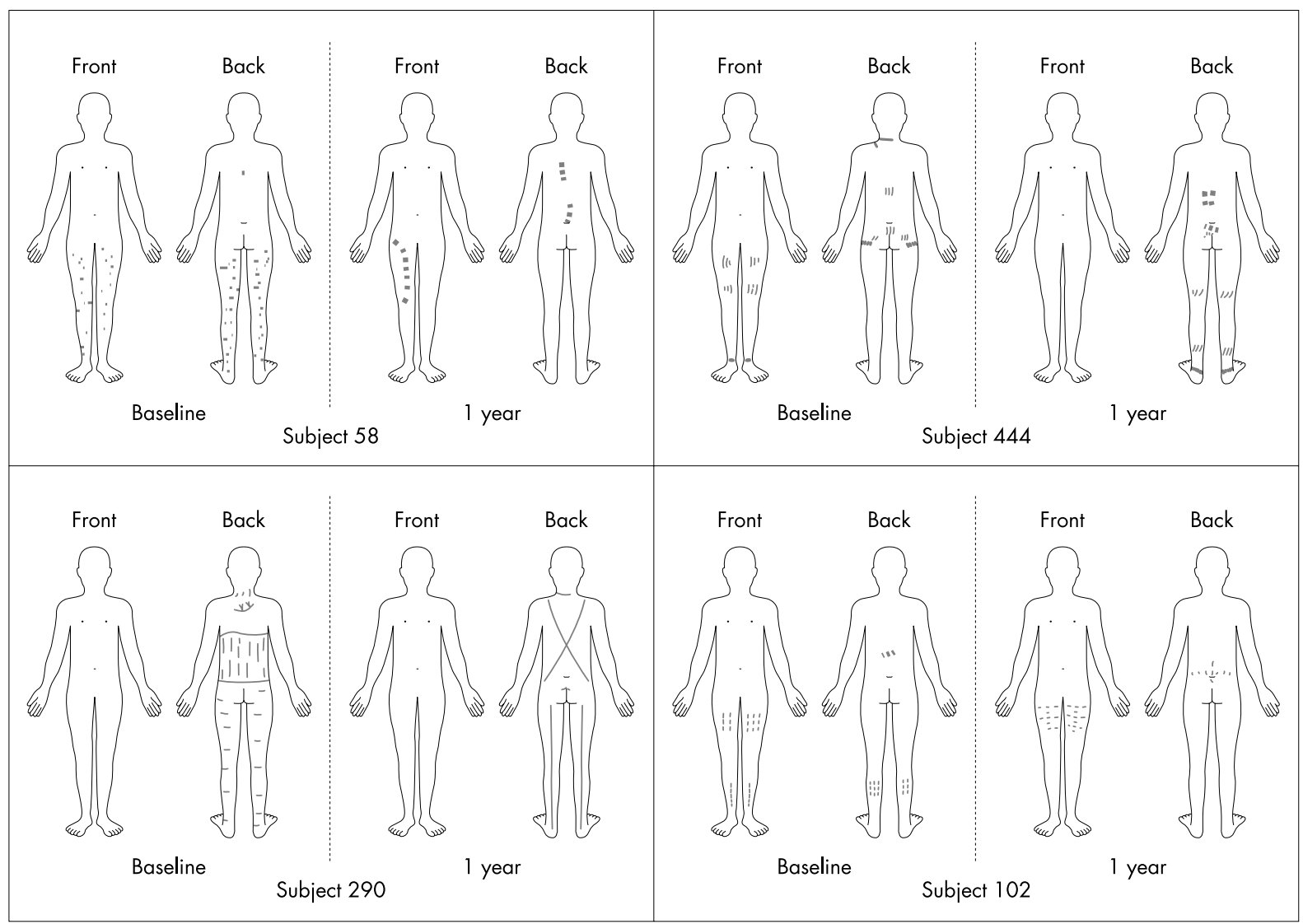

Figure 3 Pain drawing at baseline evaluation and one year follow up of the four costly cases in the control arm.

Some potential study biases and weaknesses must be acknowledged. It was found in the analysis that the workers' income was higher in the control arm and lower in the full intervention arm. As the salaries of male workers are generally higher than those of female workers, this may be a result of the observed gender imbalance caused by chance, with more males in the control arm. However, studies on the relation between gender or income and prolonged disability because of back pain have shown contradictory results, ${ }^{33}$ and such a bias for a higher risk of costly prolonged disability in one arm is unlikely.

Costs related to the job modifications recommended by the ergonomic interventions and paid by the employers were not recorded. Job modifications were suggested in 37 of 47 eligible cases (occupational and Sherbrooke model arms) and about half of the recommended job modifications were reported by employers and union representatives as having been applied. ${ }^{26}$ The related costs were rarely high and most of the changes, aimed at lowering job demands considered excessive even for a healthy worker, were potentially of benefit to noninjured co-workers as well. Since these ergonomic modification costs were not recorded, there is an underestimation (probably of moderate magnitude) of true intervention costs in the occupational and Sherbrooke model arms. However, from the insurer's perspective these costs are not to be taken into account.

It is possible that some workers had subsequent back problems not considered work related and thus not applied for workers' compensation benefits, but rather for private employer provided sickness benefits or to the Quebec Medicare system available to the general population. Also, some back pain recurrences may have been lost to follow up because follow up was based on data from the CSST administrative data, and not on data derived directly from the injured workers themselves; furthermore, some workers may have become ineligible for CSST benefits for a variety of reasons (for example, benefits denied by the CSST, job loss, retirement, welfare, moving out of the province of Quebec, other diseases, death, etc) This bias is likely to be minimal because the randomisation should have assured that this factor occur in a similar proportion in each of the four randomisation arms. Unfortunately, there was no way to verify this assumption.

As previously mentioned, the control arm behaved similarly to that expected in the natural history of occupational back pain. We were able to confirm from the study medical records that the very costly cases included in this arm were not a result of severe specific back pain conditions: the independent and blinded medical assessors who carefully examined the study patients detected no neurological abnormality and no specific diagnosis at the baseline and one year follow up evaluations. However, these patients showed obvious symptom magnification and chronic pain without defined anatomical pattern (fig $3)$. The costly case included in the occupational arm was diagnosed as a large herniated disc which was operated on 56 days after the work accident, and for this reason withdrawn from the occupational interventions. However, as the study analysis was made in intention to treat, his results appear in the occupational arm, even if he did not really receive the experimental occupational programme. In the clinical and Sherbrooke model arms no such costly cases appeared. This study reinforces the point recently underlined by several authors that conventional approaches to back pain are inadequate for some patients and should be modified. ${ }^{34}$ When the study was planned in 1989-90, the clinical rehabilitation and the occupational interventions were perceived as being very different and, for that reason, tested separately. Since then, studies have shown that effective disability management should include reassurance of workers about their condition, early return to normal activity, and supportive workplace response to injury. ${ }^{34}$ 


\section{Main messages}

- Usual medical management of back pain generates some very costly cases because of prolonged work disability.

- Work rehabilitation and workplace interventions applied to non-resolving cases of subacute back pain may allow important long term savings to workers' compensation boards and reduce the number of disability days.

When retrospectively looking at what was done in each arm, it appears that the following characteristics were found in the three experimental arms: (1) reassurance was offered through the occupational medicine physician, the back pain specialist, and/or the health care professionals (for example, occupational therapist, psychologist) in the rehabilitation interventions; (2) early return to normal activity was encouraged by all health care providers in all three experimental arms; and (3) early support in the workplace was promoted by the ergonomic intervention and/or by the "Therapeutic Return to Work" programme. This may explain the large number of DFB saved in the partial intervention arms and the even larger number of DFB saved in the Sherbrooke model arm, with lesser consequence of disease costs. This number of DFB saved in the long term may be more representative of the worker's health status than costs figures. However, some unnecessary intervention costs (occupational or clinical) could probably have been avoided if a specific analysis of the worker's needs had been made rather than applying the entire study protocol as required by the randomised trial design. What constitutes the best effective mix of interventions to reduce total costs is still unknown. We face a "black box" phenomenon which seems to be globally effective and cost-beneficial, but more precise studies of the delivered interventions are needed to better understand the way they work together and to improve their effectiveness and cost effectiveness.

\section{ACKNOWLEDGEMENTS}

The authors acknowledge the participation of the statistical department of the CSST, especially Gaston Bernard and Sylvie Blouin, for the data collection. Grant sponsor: Institut de Recherche en Santé et Sécurité au Travail du Québec (IRSST).

\section{Authors' affiliations}

P Loisel, Department of Surgery (Division of Orthopedics), Université de Sherbrooke and Centre de recherche clinique en réadaptation au travail PREVICAP, Hôpital Charles LeMoyne, 111 1, rue St-Charles Ouest, bureau 101, Longueuil, Québec, Canada, J4K 5G4

J Lemaire, Centre de recherche, Hôpital Charles LeMoyne, 3120 Taschereau Blvd, Greenfield Park, Québec, Canada, J4V 2HI $S$ Poitras, Centre de recherche clinique en réadaptation au travail PREVICAP, Hôpital Charles LeMoyne

M-J Durand, Department of Community Health Centre, Université de Sherbrooke and Centre de recherche clinique en réadaptation au travail PREVICAP, Hôpital Charles LeMoyne

F Champagne, GRIS/Faculté de médecine, Université de Montréal, C.P. 6128, succ. Centre-ville, Montréal, Québec, Canada, H3C 3J7 S Stock, Occupational and Environmental Health Unit, Montreal Department of Public Health, 1301, Sherbrooke Est Street, Montréal, Québec, Canada, H2L 1M3

B Diallo, Centre de recherche clinique en réadaptation au travail PREVICAP, Hôpital Charles LeMoyne

C Tremblay, DSPPÉ Montérégie, 5245, Cousineau Blvd, room 3000, Saint-Hubert, Québec, Canada, J3Y 6J8

\section{REFERENCES}

1 Frymoyer JW, Cats-Baril WL. An overview of the incidences and costs of low back pain. Orthop Clin North Am 1991;22:263-71.

2 Federspiel CF, Guy D, Kane D, et al. Expenditures for nonspecific back injuries in the workplace. J Occup Med 1989;31:919-24.

3 Hashemi L, Webster BS, Clancy EA. Trends in disability duration and cost of workers' compensation low back pain claims (1988-1996). J Occup Environ Med 1998;40:1 11 10-19.

4 Webster BS, Snook SH. The cost of 1989 workers' compensation low back pain claims. Spine 1994;19:1111-15.

\section{Policy implications}

- Work rehabilitation measures linked to the workplace may be of great value if implemented at the subacute stage of occupational back pain.

5 Williams DA, Feuerstein M, Durbin D, et al. Health care and indemnity costs across the natural history of disability in occupational low back pain. Spine 1998;23:2329-36.

6 Clancy EA. Cost-benefit of low back pain intervention using a classification test. Journal of Occupational Rehabilitation 1997;7:155-66.

7 Frank JW, Brooker AS, DeMaio SE, et al. Disability resulting from occupational low back pain. Part II: What do we know about secondary prevention? A review of the scientific evidence on prevention after disability begins. Spine 1996;21:2918-29.

8 Frymoyer JW, Cats-Baril W. Predictors of low back pain disability. Clin Orthop 1987(221):89-98.

9 Linton SJ. The socioeconomic impact of chronic back pain: is anyone benefiting? Pain 1998;75:163-8.

10 Nachemson AL. Newest knowledge of low back pain. A critical look Clin Orthop 1992;279:8-20.

11 Spitzer WO. Low back pain in the workplace: attainable benefits not attained. BrJ Ind Med 1993:50:385-8.

12 Waddell G. 1987 Volvo award in clinical sciences. A new clinical model for the treatment of low-back pain. Spine 1987;12:632-44

13 Cats-Baril W, Frymoyer J. The economics of spinal disorders. In: Frymoyer JW, Ducker TB, Hadler NM, et al, eds. The adult spine. Principles and practice. New York: Raven Press, 1991.

14 Cutler RB, Fishbain DA, Rosomoff HL, et al. Does nonsurgical pain center treatment of chronic pain return patients to work? A review and meta-analysis of the literature. Spine 1994;19:643-52.

15 Flor $\mathbf{H}$, Fydrich T, Turk DC. Efficacy of multidisciplinary pain treatment centers: a meta-analytic review. Pain 1992;49:221-30.

16 Lindstrom I, Ohlund C, Eek C, et al. The effect of graded activity on patients with subacute low back pain: a randomized prospective clinical study with an operant-conditioning behavioral approach. Phys Ther 1992;72:279-90.

17 Loisel P, Abenhaim L, Durand P, et al. A population-based, randomized clinical trial on back pain management. Spine 1997;22:2911-18.

18 Turk D. Efficacy of multidisciplinary pain center in the treatment of chronic pain. In: Cohen M, Campbell J, eds. Pain treatment centers at a crossroad: a practical and conceptual reappraisal. Seattle, WA: IASP Press, 1996:257-73

19 Yassi A, Tate R, Cooper JE, et al. Early intervention for back-injured nurses at a large canadian tertiary care hospital-an evaluation of the effectiveness and cost benefits of a two-year pilot project. Occup Med 1995:45:209-14.

20 Goossens $M$, Evers S. Economic evaluation of back pain interventions Journal of Occupational Rehabilitation 1997;7:15-32

21 Mitchell CS. Outcome studies in industry: cost-effectiveness of cumulative trauma disorder prevention. Am J Ind Med 1996;29:689-96.

22 Solomon DH, Bates DW, Panush RS, et al. Costs, outcomes, and patient satisfaction by provider type for patients with rheumatic and musculoskeletal conditions: a critical review of the literature and proposed methodologic standards. Ann Intern Med 1997; 127:52-60.

23 Elders LAM, van der Beek AJ, Burdorf A. Return to work after sickness absence due to back disorders - a systematic review on intervention strategies. Int Arch Occup Environ Health 2000;73:339-48.

24 Abenhaim L, Suissa S. Importance and economic burden of occupational back pain: a study of 2,500 cases representative of Quebec. J Occup Med 1987:29:670-4.

25 Loisel P, Durand P, Abenhaim L, et al. Management of occupational back pain: the Sherbrooke model. Results of a pilot and feasibility study. Occup Environ Med 1994;51:597-602.

26 Loisel P, Gosselin L, Durand P, et al. Implementation of a participatory ergonomics program in the rehabilitation of workers suffering from subacute back pain. App/ Ergon 2001;32:53-60.

27 Durand MJ, Loisel P. Therapeutic return to work: rehabilitation in the workplace. Work 2001;17:57-63

28 Drummond MF, Stoddart GL, Torrance GW. Methods for economic evaluation of health care programs. New York: Oxford University Press, 1987.

29 Statistics Canada. Cansim data bank: series p20500 and 205085. Ottawa: Statistics Canada, 1998

30 OECD. Total expenditure on health per capita. URL: http:// www.oecd.org/els/health/sad 15.htm, 1999.

31 OECD. GDP per capita. URL: http:/www.oecd.org/std/ppps, 1999

32 Spitzer WO, LeBlanc FE, Dupuis M. Scientific approach to the assessment and management of activity-related spinal disorders. A monograph for clinicians. Report of the Quebec Task Force on Spinal Disorders. Spine 1987;12(7 suppl):S1-59.

33 Valat JP, Goupille P, Vedere V. Low back pain: risk factors for chronicity. Rev Rhum Engl Ed 1997;64:189-94

34 Frank J, Sinclair S, Hogg-Johnson S, et al. Preventing disability from work-related low-back pain. New evidence gives new hope-if we can just get all the players onside. CMAJ 1998;158:1625-31. 